\title{
Out of sight, out of mind
}

\author{
Charles G. D. Brooker and Martin Brown
}

\section{Summary}

As a result of the psychiatric hospital closure programme the use of private sector facilities for those needing longer-term care and support has increased. However, local rehabilitation services may be a better solution than out of area treatment.

\section{Declaration of interest}

None.

\section{Copyright and usage}

(c) The Royal College of Psychiatrists 2015.
Charles G. D. Brooker (pictured) is a honorary professor of criminal justice and mental health in the Department of Criminology at Royal Holloway. Martin Brown was head of mental health policy at the Department of Health (1995-2001) and Director of high secure services at Ashworth Hospital (2008-2011). He is a consultant adviser to the World Health Organization on mental health policy and practice.

\section{Background}

Bed numbers in large psychiatric hospitals peaked in the early 1950s. In 1962 the Hospital Plan for England and Wales predicted the closure of half of these beds by 1975. The decision to close the hospitals and move to a range of community-based services was set out in 1975 in the Better Services for the Mentally Ill white paper. ${ }^{1}$ The estimated timescale of 25 years was remarkably prescient, most of the 100 or so had closed by 2000 (the peak year of 1995 saw 17 close) with the remainder shut by 2010 (Fig.1). ${ }^{2}$ The closure of the hospitals, and the development of community services had multi-party political support. In retrospect, the scale and pace of change was remarkable.

\section{The rise of private sector placements}

One legacy of the psychiatric hospital closure programme has been the use of private sector facilities for those needing longer-term care and support, or who are deemed to be challenging to local services, i.e. treatment resistant, have highly complex needs and are reluctant to engage. These placements are know as 'out of area treatments' (OATs). It has been argued that the use of OATs has created virtual asylums. ${ }^{3,4}$ Smaller scale but often locked establishments with little or no focus on quality assurance and decreasing scrutiny from regulators. A depressing resonance with the private mad houses of the 19th century.

Subsequent mental health policy has focused more on the care processes, and teams needed (for example, as described in the National Service Framework for Mental Health (NSF) and subsequent Policy Implementation Guides), with specific attention on early detection, rapid treatment and reduced admission. But there is one group of users who have been largely ignored. They have longer-term needs, mostly with psychosis and they need extended periods of admission with considerable ongoing support and care as a result of the complexity of their problems. In short, they need rehabilitation - something that was largely absent from the NSF, which set out a plan for the development of services over a period of 10 years from 1999 to 2009. As Holloway ${ }^{5}$ noted in this context: some effective rehabilitation teams were rebadged as assertive outreach teams; health and social care placements were spot purchased by

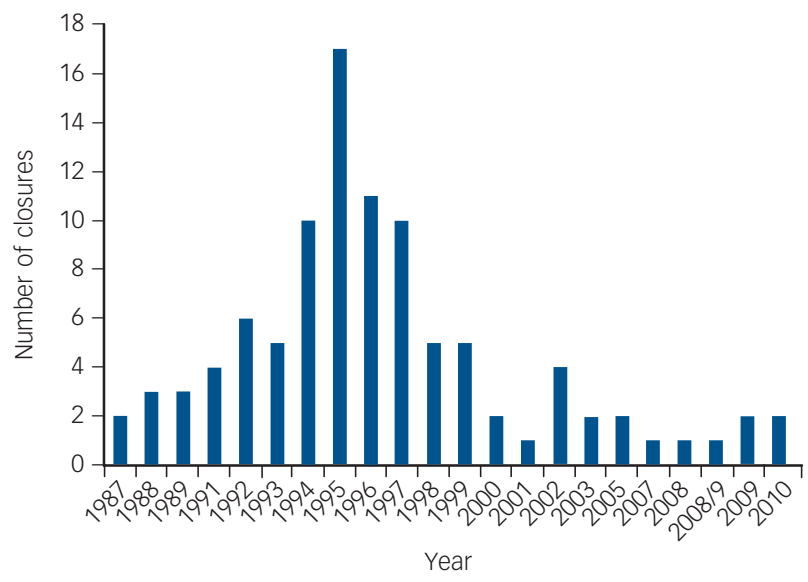

Fig. 1 The frequency of closure of the large psychiatric hospitals in England by year.

Source: The Asylums List (2014). ${ }^{2}$

commissioners creating a virtual asylum largely in the private sector; long-stay in-patient beds did not fit well with a managerial ethos focused on decreased lengths of time in in-patient beds; failure to respond to treatment for psychosis was downplayed by evidence-based practice; psychiatric rehabilitation became seen as a redundant concept in the midst of hospital closure. In short, Holloway concluded that psychiatric rehabilitation became unfashionable in a world supposedly driven by functional, evidence-based, mental health teams and the harsh realities of budgetary restriction.

Despite the loss of coherent rehabilitation services during the implementation of the NSF, Killaspy et al $(2005)^{6}$ in a national survey identified 2200 National Health Service (NHS) rehabilitation beds. Many of these services also employed community rehabilitation teams. In addition, however, Hatfield and colleagues ${ }^{7}$ showed just how variable the ongoing use of private sector rehabilitation placements was for those with a diagnosis of psychosis. This study took place in seven strategic health authority areas covering some $24 \%$ of the total English population. In total, 3500 adults were placed, $40 \%$ of whom had a psychosis. The proportion of placements located over 20 miles or more from the adult's neighbourhood varied from 16 to $54 \%$.

\section{The financial cost of OATs}

How much do OATs cost? Ryan et $\mathrm{l}^{8}$ calculated the average cost of an OAT, for 70 people with a severe and enduring mental illness, from one primary care trust and one social services department. The majority of this group were placed in the private sector with 
an annual cost of $£ 30800$ per annum. In addition, $64 \%$ were not on the care programme approach; most were in locked facilities although informal patients (79\%); 50\% had no clinical history taken and nearly one-third required supported accommodation rather than independent care.

In an article by David Brindle ${ }^{9}$ Killaspy's work with the Royal College of Psychiatry's Policy Unit was cited. They sent a Freedom of Information request to all English primary care trusts and local authorities to try to get a clearer national picture of the number and cost of OATs. The survey found a total of 6280 OATs, costing

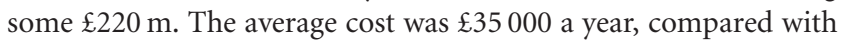
$£ 22000$ for an equivalent placement in a local rehabilitation service. Thus, an NHS placement is $32 \%$ less expensive than the private sector equivalent. Extrapolated to take account of nonrespondents, overall spending on OATs was calculated at

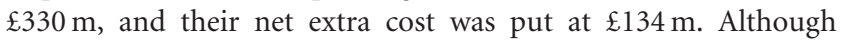
not all OATs are deemed replaceable, Killaspy thinks that almost all those (half the total) made by local authorities are likely to be so, as well as 'a significant proportion' of those more complex cases handled by primary care trusts. On this basis, much of the $\mathfrak{E} 134 \mathrm{~m}$ extra cost could be saved.

\section{A better way forward?}

Killaspy and colleagues (2009) had already demonstrated the feasibility of the argument in a formal study based in London. Her team assessed service users in OATs for suitability for relocation to local rehabilitation and supported accommodation. ${ }^{10}$ The study compared the characteristics of individuals placed in OATs with those of local rehabilitation service users in order to identify gaps in local provision. Over the first 30 months, 51 individuals placed in OATs were identified and 40 reviewed. Standardised assessment data were compared with local rehabilitation service users' data. The findings from the study showed that individuals placed in OATs had a greater range of diagnoses and more had alcohol dependency than local service users. Ratings of social function were similar. Of 25 individuals $(63 \%)$ in OATs assessed as suitable to move, $13(33 \%)$ relocated, all to more independent accommodation. Associated financial flows were reinvested into new local highly supported flats. The study concluded that a significant proportion of individuals placed in OATs could be successfully relocated to more independent local facilities.

In recent years, more attention has been paid to the needs of this client group. Rehabilitation services can now become accredited through the AIMS system, an initiative of the Royal College of Psychiatrists' Centre for Quality Improvement. In 2011, The Royal College of Psychiatrists published a toolkit on good practice in relation to OATs, which was commissioned by the Department of Health as part of their QIPP (Quality, Innovation, Productivity and Prevention) initiative. ${ }^{11}$ The Joint Commissioning Panel for Mental Health also emphasised the need for local and integrated responses. ${ }^{12}$ In recent years there have been encouraging signs of a revitalised approach to commissioning in this area. For example, in Tees, Esk and Wear Valley NHS Foundation Trust, the West Park Unit for people with long-term needs and challenging behaviour practice intensive rehabilitation focused on recovery. The Unit is AIMS accredited. In another example, a consortium of commissioners in Lancashire are launching an initiative in partnership with local providers and social care organisations to develop local alternatives. Key among their ideas is the dedicated case manager for people with longterm needs placed out of area.

Despite these examples of innovation above, the anecdotal evidence is that rehabilitation services are facing serious cuts and reconfigurations of their services. The demonstrable determination of those working in the rehabilitation field is heartening. ${ }^{13}$ But is it enough? There is a natural temptation to call for a national policy to set out the ways for providing the best service for this complex population. But policy documents can be a two-edged sword; limiting innovation, as they standardise practice. Perhaps it is better to enable a profession-wide dialogue, backed with the latest expertise and practice, based on the evidence that is now emerging. Can it really be sensible to continue wasting money on spot-contracted OATs, at a time when there is considerable pressure on both mental health and local authority budgets, instead of investing in well-trained staff working in local rehabilitation teams, supported by dedicated case managers all underpinned by re-commissioned 'cost and volume' contracts i.e. where commissioners guarantee to buy a minimum level of service at a set price with the option to add additional placements if needed. Whole system commissioning and provision is required, reducing the gap between organisations, creating a freeflowing pathway that hastens improvement for this deserving group.

Charles G. D. Brooker, MSc, PhD, Honorary Professor, Department of Criminology, Royal Holloway, University of London, Egham; Martin Brown Honorary Professor, University of York School of Health Sciences, York, UK

Correspondence: Charles G. D. Brooker, Department of Criminology, Royal Holloway, Egham Hill, Surrey TW20 OEX, UK. Email: charlie.brooker@ rhul.ac.uk

First received 12 Nov 2014, final revision 24 Apr 2015, accepted 13 May 2015

\section{References}

1 Department of Health and Social Security. Better Services for the Mentally III. HMSO, 1975.

2 The Time Chamber. The Asylums List. The Time Chamber, 2014.

3 Killaspy $\mathrm{H}$. From the asylum to community care: learning from experience. Br Med Bull 2006; 79-80: 245-58.

4 Poole R, Ryan T, Pearsall A. The NHS, the private sector and the virtual asylum. BMJ 2002; 325: 349-50.

5 Holloway F. The Forgotten Need for Rehabilitation in Contemporary Mental Health Services: Position Statement from the Executive Committee of the Faculty of Rehabilitation and Social Psychiatry, Royal College of Psychiatrists. Royal College of Psychiatrists, 2005.

6 Killaspy H, Harden C, Holloway F, King M. What do mental health rehabilitation services do and what are they for? A national survey in England. J Mental Health 2005; 14: 157-65.

7 Hatfield B, Ryan T, Simpson V, Sharma I. Independent sector mental health care: a 1-day census of private and voluntary sector placements in seven Strategic Health Authority areas in England. Health Soc Care Community 2007; 15: 407-16.

8 Ryan T, Pearsall A, Hatfield B, Poole R. Long term care for serious mental illness outside the NHS: a study of out of area placements. J Ment Health 2004; 13: 425-9.

9 Brindle D. Millions wasted on treating mentally ill away from their communities. The Guardian 2010; 14 April.

10 Killaspy H, Rambarran D, Harden C, Fearon D, Caren G, McClinton K. A comparison of service users placed out of their local area and local rehabilitation service users. J Ment Health 2009; 18: 111-20.

11 Ryan $\mathrm{T}$, Davies G, Bennett A, Meier R, Killaspy H. In Sight and In Mind: A Toolkit to Reduce the Use of Out of Area Mental Health Services. National Mental Health Development Unit, 2011

12 Joint Commissioning Panel for Mental Health. Rehabilitation Services for People with Complex Mental Health Needs: Ten Key Messages for Commissioners (http://www.jcpmh.info/wp-content/uploads/10keymsgsrehabilitation.pdf). JCPMH, 2013.

13 Killaspy H, Marston L, Green N, Harrison I, Leon M, Cook S, et al. Clinical effectiveness of a staff training intervention in mental health inpatient rehabilitation units designed to increase patients' engagement in activities (the Rehabilitation Effectiveness for Activities for Life [REAL] study): singleblind, cluster randomised controlled trial. Lancet Psychiatry 2015; 2: 38-48. 